\title{
Cutaneous Fibrous Histiocytoma, Histiocytic Variant
}

National Cancer Institute

\section{Source}

National Cancer Institute. Cutaneous Fibrous Histiocytoma, Histiocytic Variant. NCI

Thesaurus. Code C49077.

A morphologic variant of cutaneous fibrous histiocytoma characterized by the presence of xanthomatous fibrohistiocytic cells, giant cells, and hemosiderin deposition. 